\title{
Palliative care for
} cancer patients current trends and
models in the ' 90 s

\author{
By Marilyn J. Deachman
}

\section{Abstract}

Quality care for palliative cancer patients is becoming even more challenging as health care costs continue to rise and budgets to shrink. Significant problems in managing care, for example, pain and other symptoms, persist due to inadequate education; lack of clinical expertise and trained professionals to provide services; unavailability of some treatment options; and restrictions on financial resources. A comprehensive, collaborative, multidisciplinary approach to palliative care services can be provided with a comfortable and efficient flow between hospital and home. Guidelines for standardization of palliative care services would assist in: reducing inefficient practices; optimizing most effective practice approaches; decreasing duplication of services; and providing more comprehensive service to palliative patients and their families.

\section{Introduction}

Health care professionals concerned with the management of cancer care are currently faced with a number of daunting challenges. Demographic trends in North America show a growing and aging population, and we can expect a concomitant rise in new cancer cases, and recurrent and secondary cases as well, as we move into the next millennium. Many of these new cases will occur in older patients, presenting with more difficult symptom complexes. This burgeoning caseload will emerge at a time when health care resources are being stretched thin as governments struggle to cope with increasing health care costs and runaway deficits.

As health care professionals, we are constantly challenged to find more cost-effective approaches to the management of cancer care without compromising the quality of cancer programs. For example, recent surveys (Cecchin, 1992) have demonstrated that a significant proportion of cancer patients do not receive sufficient medications to adequately control their pain. This is an unfortunate situation, especially in light of recent advances in the understanding of the optimal use of opioid and non-opioid analgesics, adjuvant medications and nonpharmacological approaches to the treatment of cancer pain.

Work is progressing on a number of fronts to deal with these important issues. The Cancer 2000 Task Force has been examining cancer care and palliative care in Canada and has formulated strategies and goals for the coordination of care in Canada. New models of palliative care have

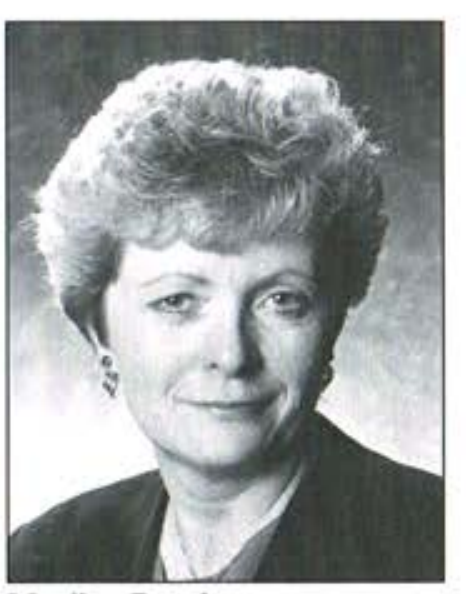

Marilyn Deachman been developed that present a more practical and humane frame of reference for the treatment of cancer. For example, in several provinces, community health care programs have been developed with the goal of providing complete palliative care in the home.

One of the keys to success on all of these fronts will be effective education and information sharing programs. Increased emphasis on the development of training programs and guidelines for cancer care, for example pain management, will help to establish the quality and portability of skills, and provide a framework for disseminating the results of new research to health care professionals. This can be cost-effective without jeopardizing quality care.

\section{Cancer 2000 on palliative care}

The Cancer 2000 Task Force, which was established in 1989, solicited input from a number of national and provincial cancer organizations, and from this feedback developed a framework for cooperation and coordination of cancer control efforts.

A number of advisory boards were established to examine and report on specific areas of cancer control, one of which focused specifically on palliative care for cancer patients. In its report to the Cancer 2000 Task Force, the Palliative Care Advisory Board observed that cancer control efforts in Canada are largely directed towards the development of expensive and high-tech diagnostic and treatment methods, at the expense of palliative care programs which are currently underdeveloped and underfunded. Novel interventions and treatments are necessary and should certainly be applied in cases where they can be expected to benefit the patient. However, the need for a balanced approach to treatment cannot be overstated. It must be recognized that every seriously ill patient will vacillate between the desire to extend life through aggressive interventions and the desire to receive specialized palliative care in preparation for death.

A second recommendation of the Palliative Care Advisory Board (PCAB) was to encourage the development of home care programs for patients by health care professionals. By freeing up beds and other hospital resources, these programs permit the hospital to devote these resources to the care of patients who do not have the option of receiving care at home. In addition, the patient can be cared for in a familiar

\section{SOINS PALLIATIFS POUR LES PATIENTS ATTEINTS DU CANCER - TENDANCES ET MODĖLES DES ANNÉES 90}

\section{ABRÉGÉ}

La qualité des soins dispensés aux cancéreux en traitement palliatif est un défi de plus en plus sérieux alors que le coût des soins de santé augmente et que les budgets diminuent. Des problèmes significatifs persistent dans la gestion des soins, la gestion de la douleur et d'autres symptômes. Ceci est dû à un système éducatif inadapté; un manque de compétences cliniques et de professionnels formés pour dispenser ces soins; une indisponibilité dans le choix de certains traitements et des restrictions au niveau des ressources financières. On peut offrir une approche des services en soins palliatifs basée sur la compréhension, la collaboration et les échanges pluridisciplinaires si l'on privilégie une transition aisée et efficace entre l'hôpital et la maison. Des lignes directrices visant la standardisation des services en soins palliatifs contribueraient à une réduction des pratiques inefficaces. Elles optimaliseraient aussi les approches cliniques bien établies, diminueraient le chevauchement de services et offriraient un soutien plus adapté aux patients en soins palliatifs et à leurs familles.

Marilyn Deachman, RN, BA, is Supportive Care Practitioner at Credit Valley Hospital, Mississauga, Ontario. 
environment, thus reducing some of the stress associated with hospitalization. To this end, the PCAB stressed the need for good working models for palliative care, and effective training programs for multidisciplinary palliative care teams. These programs are of benefit not only to the patient and family, but to the hospital and community as well. In order to make care at home accessible in all parts of the country, the advisory board urged the development of regional centres to assume responsibility for teaching, research and consultation, and to provide a base for specialized palliative home care.

The Palliative Care Advisory Board also recommended that greater efforts be applied to palliative care research, with the goal of designing preventive models of palliative care. It is very important, especially in the outpatient setting, that all members of the palliative care team be able to anticipate and respond to contingencies that may arise as a result of the disease process or side effects of treatment. Better predictive models will also permit more accurate judgments as to which patients can be expected to benefit the most and better targeting of palliative care resources.

\section{Models of palliative care}

The main importance of obtaining good working models of palliative care lies in their power to encapsulate knowledge and provide a frame of reference for palliative care providers. Models of palliative care have undergone a steady evolution in recent years, and will continue to evolve as we gain more experience and learn to share this experience more effectively. Recently, this process has been driven by the emergence of AIDS, the hospice movement, and the continuing expansion of medical options in the treatment of cancer.

The evolution of palliative care models is shown in Figures $1 \mathrm{a}, 1 \mathrm{~b}$ and Ic. In the older models, the boundary between acute care and palliative care was static and well-defined. Patients received aggressive acute treatments in an attempt to cure their disease or put it into remission until it became apparent that further interventions would be futile, at which point treatment would enter the palliative mode. In the $1980 \mathrm{~s}$, this view changed as it became recognized that there may be a need for some aspects of palliative care even while active treatment is being pursued. Some patients may demand acute care right up to the moment of their death. Or conversely, what is perceived to be active treatment might be provided to enhance palliation. More recent models expand on this view, recognizing the need for a balanced approach to treatment throughout the course of the patient's illness.

One recent model, developed at the Victoria Hospice Society in Victoria, British Columbia, employs a colour spectrum to represent the continuum of palliative care. Blue and yellow are used at the extremes of the spectrum to represent the acute modalities and reactive modalities of palliative treatment, respectively. When treatment is in the blue mode, acute treatments are being applied in an attempt to restore the patient to comfort, modify the disease process, and possibly extend life, for example, treatment of hyper-calcaemia. The treatment modality shifts into the yellow mode when emergent side effects or a sudden change in the patient's condition precipitates a palliative care crisis that demands immediate attention, for example, rapid escalation of pain.

Green is used in the broad middle range of the spectrum to represent the stable mode of palliative care, where the patient's symptoms and side effects of treatment are under control and acute interventions are being kept to a minimum. Patient comfort, pain control, counseling and reassurance, and the routine management of side effects are the foci of attention when treatment is in the green mode. For example, in this stable green mode of palliative care, opioid analgesics are often the mainstay of pain management. With the correct and optimal use of these drugs, patients who might otherwise suffer severe and debilitating pain are able to remain alert, active and pain-free.

Balance is a key element of this model, and the goal of palliative care is to maintain treatment in the green modality insofar as that is possible. However, health care professionals working with cancer patients must be capable of taking treatment into the blue or yellow modes if a change in a patient's condition warrants a change in treatment. To this end, it is necessary to recognize when a patient would benefit from a change of treatment, and to respond quickly and aggressively to emergent side effects of a patient's therapy.

When treatment is in the blue or yellow modes, the patient and caregivers are often subject to considerable anxiety stemming from

Figure One A: Older models of palliative care made a sharp distinction between the active and palliative modes of treatment. (Anderson, Downing, Braithwaite, et al., 1993).

\section{Old Model}

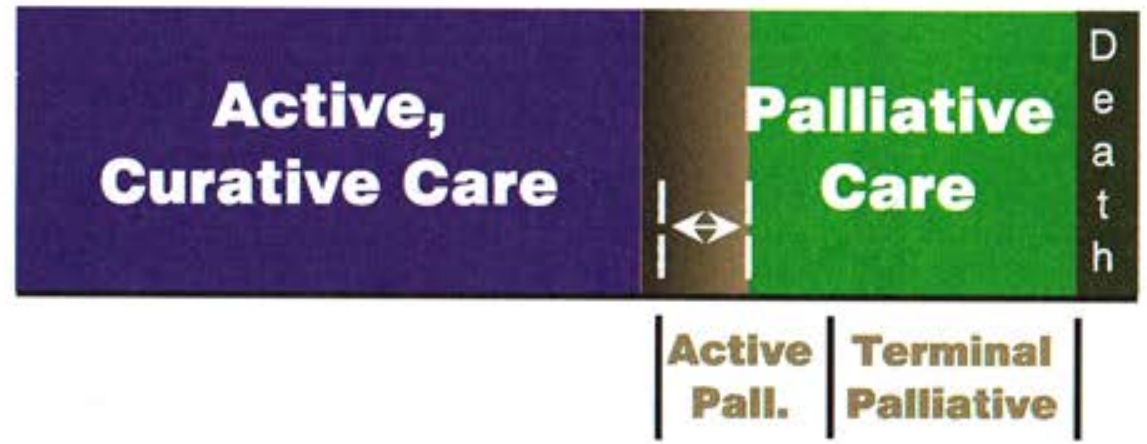

Figure One B: With the emergence of AIDS in the 1980s, the hospice view of medical treatment evolved, which recognized that there was considerable overlap between the active and palliative modes of treatment. (Anderson, Downing, Braithwaite, et al., 1993).

\section{Newer Model (AIDS) - 1988}

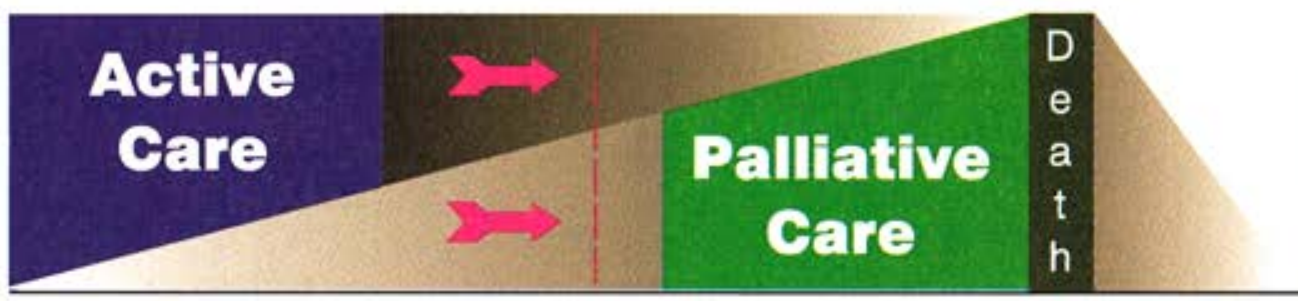


uncertainty about the results of treatment. Most acute treatment methods may be associated with some risk to the patient, and the methods of dealing with palliative care crises such as dyspnea or pre-death restlessness may actually accelerate the patient's death as a consequence but not as a purpose. The Victoria model also attempts to encapsulate these tensions and internal conflicts that are frequently experienced by patients and caregivers alike during the course of treatment.

Lateral tension represents the patient's internal struggle between the desire to extend his life through acute care and the desire to receive good palliative care while he prepares for death. For example, the patient may request regular follow-up $\mathrm{x}$-rays to know the status of the disease, but may not want aggressive interventions, regardless of the results. It is important for caregivers to be sensitive to the patient's state vis-a-vis this dynamic, as it can be a source of conflict between the patient and caregivers. Vertical tension represents the internal conflict and anxiety that arises in caregivers when they are forced to choose between providing procedures that may give the patient some benefit but which may have risks or unacceptable side effects, or avoiding these procedures and leaving the patient with poor control of his symptoms. This kind of tension is minimized when treatment is maintained in the green mode of palliative care.

Lateral and vertical tensions are minimized by a balanced approach to palliative care, and are increased when the treatment modality shifts out of the stable green mode and into the blue or yellow mode of treatment. Although such shifts should be of a temporary nature, with treatment returning to the green mode as soon as the patient's condition is stable, there is the risk of a consistent skew effect. When treatment is consistently skewed toward the blue end of the spectrum, clinicians may resort to numerous tests and investigations, various novel

Figure One C: The Victoria model uses a colour spectrum to present a more comprehensive view of palliative care. The colours represent the different modalities of treatment that arise in the care of terminally ill patients, ranging from acute care (blue), through a broad middle range of stable palliative care (green), to the urgent mode of treatment that is sometimes required to deal with palliative care crises (yellow) |Anderson, Downing, Braithwaite et al., 1993].

\section{Victoria BGY Palliative Care Model for '90s}
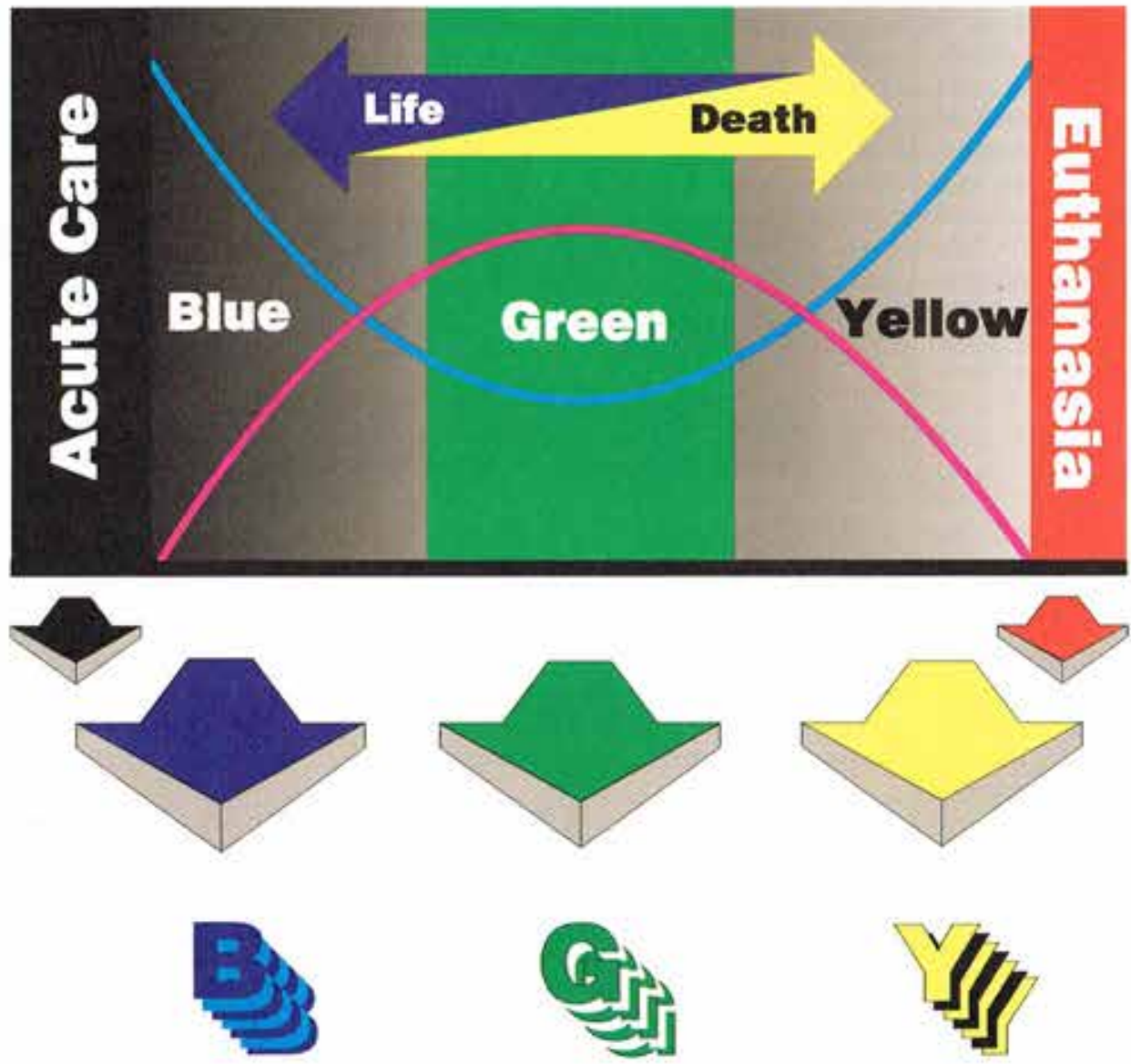
1. Spectrum
2. Lateral Tension
3. Vertical Tension
4. Approach
5. Profile
5 Colours BBGYR
Life \& Death
Emotional
BGY Approaches
Degree of Balance 
treatments, or virtually any measure that may possibly extend the patient's life. This may be a source of conflict if it exceeds the patient's level of tolerance for these disruptive interventions.

The mode of treatment is skewed toward the yellow if it consistently leaves patients in poor control of their symptoms or induces side effects that require urgent attention. This situation could arise if the patient or family has misplaced fears concerning opioid tolerance and addiction, or if opioids are applied to treat pain that is typically less responsive to opioids, such as neuropathic pain. A yellow skew can often be avoided or corrected through the aggressive and appropriate use of opioid, non-opioid and adjuvant medications in accordance with established guidelines, as well as non-pharmacological approaches to care. However, as crisis situations will occasionally arise even with the most attentive care, it is of the greatest importance that palliative care professionals maintain their skills in dealing with these events, whether the patient is being cared for in hospital or at home.

\section{Outpatient palliative care: A team approach}

As health care costs continue to rise and budgets to shrink, hospitals are being pressured to streamline their operations and maximize their use of resources. To do this without compromising the quality of patient care will be one of the biggest challenges to be faced by hospitals in the 1990s. Novel approaches to the provision of care will be required. One such approach that has shown considerable promise in recent years is the development of community health care programs, whereby patients who do not require acute treatments but acute care are treated in their homes on an outpatient basis. In the past, infusion therapy was used primarily in the hospital setting to deliver very high doses of opioids in the terminal stages of cancer. Many patients associated this form of therapy with the last intervention prior to death. With the development of portable infusion devices, the expansion of home parenteral pharmacy services, and community health care programs, however, many patients are now able to receive infusion therapy on an outpatient basis. Complete palliative care at home is provided by dedicated, multidisciplinary teams of health care professionals and volunteers, working under the direction of the family physician.

Figure Two illustrates the dynamics of one team approach to community care. The family physician maintains a close relationship with the patient and family, coordinating the services of other health care professionals on their behalf. The nurse consults with the patient and family initially to set up a flexible palliative care plan, assessing the special needs of the patient and family and negotiating with the home caregivers as to their responsibilities. Once outpatient care has been established, the nurse makes regular visits to the home in order to assess the patient's condition and to report changes in the patient's condition back to the team. The oncologist may also be involved, assisting in managing the transition from hospital to home care and as a consultant in symptom management. The pharmacist acts as a provider of drugs and equipment, as well as information regarding pharmacotherapy not only to other team members, but also to the patient and family. Responsibility for on-call status and routine tasks should be coordinated as much as possible through the family doctor and the community health care team. This ultimately increases everyone's effectiveness as team players.

All team members, including caregivers from the patient's family, should be kept informed regarding the patient's treatment and possible side effects of therapy, in order to ensure recognition and quick response to changes in the patient's condition. To this end, some degree of interdisciplinary training is required of each team member. This training can be provided in a cost-effective manner through shared educational programs that are designed to be accessible to all members of the team. When it is appropriate, training programs should be designed to be accessible to the family as well.

By ensuring uniformity of content, shared educational programs also help to establish continuity and consistency of care, thereby facilitating transitions in the health care setting. Outpatient programs such as infusion therapy should be structured so that they can be similarly applied either in the hospital or the home setting. This allows for continuity of care, and saves time in patient and family counseling. Furthermore, uniformity of programs across the country will allow patients greater freedom to visit or move to another community if they so desire.

When outpatient programs are well-designed and maintained, they work to the benefit of all parties. Patients who qualify for and elect to receive outpatient care are able to receive care in the home surrounded by their families, with the assurance of complete medical support from the palliative care team. The family physician, struggling to cope with an ever-increasing case load, is able to share some of his or her responsibilities with other members of the team and to benefit from their expertise and support as well. The hospital and community benefit as beds and other precious hospital resources are freed for allocation to patients who are not eligible or appropriate for outpatient care.

\section{Conclusions}

The Cancer 2000 experience has shown that a significant proportion of cancer patients still do not receive adequate symptom management. Given recent advances in our understanding of the use of opioid and non-opioid analgesics, adjuvant medications and non-pharmacological approaches for the treatment of cancer pain, this is an unfortunate and unnecessary state of affairs. It is especially disturbing in light of current demographic trends indicating that our population is growing and aging, signaling a rising rate of incidence of cancer and a growing case load for health care professionals. This state of affairs presents a challenge to health care professionals to exert every effort to remedy.

A number of recent developments in the field of palliative care

Figure Two: Coordinating palliative care in the community: A team approach.

\section{COORDINATION OF PALLIATIVE CARE SERVICES IN THE COMMUNITY}

\section{A "TEAM" APPROACH MODEL}
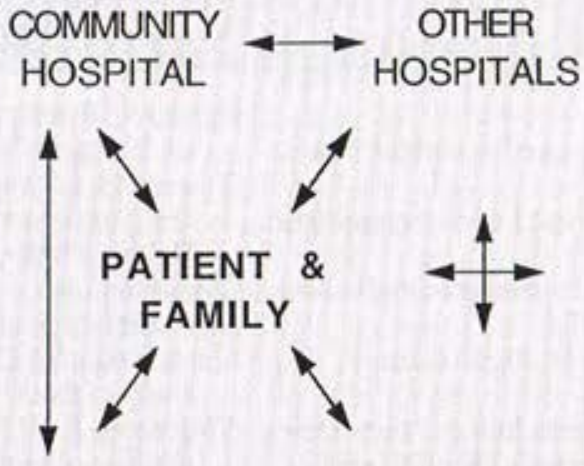

PATIENT \& FAMILY

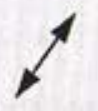

\&
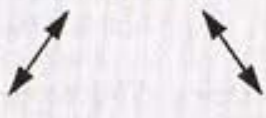

HOME CARE

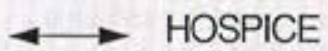

HOSPICE

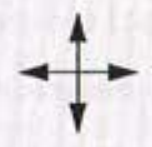

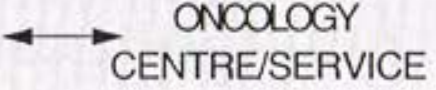

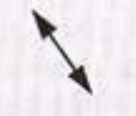

FAMILY DOCTOR

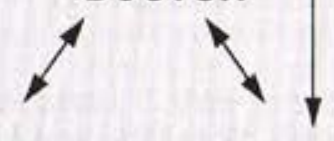

SUPPORT SERVICES 
present encouraging signs that this situation may be improving. New models of palliative care present a humane and practical frame of reference for palliative care professionals and volunteers. The current trend toward the provision of palliative care in the outpatient setting, through community health programs and multidisciplinary palliative care teams, provides many terminally ill patients with the opportunity to receive complete care in the comfort and privacy of their own homes, where they can be attended to by members of their own families and friends.

\section{References}

Anderson, M.D., Downing, M.G., Braithwaite, D.L., et al. (1993). Medical care of the dying. (2nd ed.) Victoria Hospice Society. Victoria, B.C.

Bayer, R., Callahan, D., Fletcher, J., Hodgson, T., Jennings, B., Monsees, D., Sieverts, S., Veatch, R. (1983). The care of the terminally ill: Morality and economics. New England Journal of Medicine, 309, 1490-94.

Bowling, A. (1983). The hospitalization of death: Should more people die at home? Journal of Medical Ethics, 9, 158-61.

Boyd, K. (1993). Palliative care in the community: Views of general practitioners and district nurses in East London. Journal of Palliative Care, 9(2), Global Exchange, 33-38.

Boyd, K. (1992). The working patterns of hospice based home care teams. Palliative Medicine, 6(2), 131-139.

Brown, P., Davies, B., Martens, N. (1990). Families in supportive care. Part II. Palliative care at home: A viable care setting. Journal of Palliative Care, 6(3), 21-27.

Cartwright, A. (1990). The role of the general practitioner in caring for people in the last year of their lives. London: King's Fund.

Cassell, E.T. (1991). Relief of suffering: The doctor's mandate. Journal of Palliative Care, 7(4), 3-4.

Cecchin, A. (1992). Cancer pain management: A Canadian perspective. Pain Management Newsletter, 5(1), 3-4.

Cleeland, C.S. (1987). Barriers to the management of cancer pain. Oncology (Suppl.). 1, 19-26.

Clench, P. (1984). Managing to care in community services for the terminally ill. London: Patten Press.

Coyle, N., Loscalzo, M., Bailey, L. (1989). Supportive home care for the advanced cancer patient family. Handbook of Psychooncology. Oxford University Press, New York, 598-606.

Daut, R.L., Cleeland, C.S. (1982). The prevalence and severity of pain in cancer. Cancer, 50, 1913-1918.

Davies, B., Reimer, J., Martens, N. (1990). Families in supportive care, Part I: The transition of fading away - The nature of the transition. Journal of Palliative Care, 6(3), 12-20.

Deachman, M.J. (1989). A nursing role in pain management with a portable pain pump. The Canadian Journal of Home Care and Rehabilitation, 2(1).

Deachman, M.J. (1990). The challenges of pain management. Focus on Oncology - Ontario Oncology Association for Health Professionals Newsletter. 11(3).

Deachman, M.J., Howell, D. (1991, 1994). Supportive care at home. (booklet). Knoll Pharmaceuticals Canada.

Deachman, M.J., Uyeyama, A. (1994). Doing what I can - Supportive care at home for the seriously ill. (Video)

Ferrel, B., Schneider, C. (1988). Experience and management of cancer pain at home. Cancer Nursing. 11(2), 84-90.

Foley, K.M. (1989). Controversies in Cancer Pain. Cancer, 63, 2257-2265.

Haines, A., Booroff, A. (1986). Terminal care at home: Perspective from general practice. British Medical Journal, 292, 1051-1053.

Hayes, H. (1985). Hypodermoclysis for symptom control in terminal cancer. Canadian Family Physician, 31, 1253-1256.

Huffman, M.C. (1993). Family physicians and the health care team. ranadian Family Physician, 39, 2165-2170.
The key to improving our palliative care services will be to develop better guidelines for palliative care professionals working with cancer patients. In spite of an abundance of research in the field, the development and effective promotion of such guidelines has been slow. In view of current economic trends, whereby the economic base for health care is steadily shrinking, it is of vital importance to accelerate this process as standardization can help to reduce duplication of services and inefficient practices.

Kearney, M. (1992). Palliative medicine - Just another speciality? Palliative Medicine, 6, 39-46.

Kerr, I.G., Sone, M., DeAngelis, C., Iscoe, N., MacKenzie, R., Schueller, T. (1988). Continuous narcotic infusion with patient controlled analgesia for chronic cancer in outpatients. Annals of Internal Medicine, 105, 554-557.

Lichter, I. (1987). Communication in cancer care. Churchill Livingstone: New York.

Lichter, I., Hunt, E. (1990). The last 48 hours of life. Journal of Palliative Care, 6(4), 7-15.

Lubin, S. (1992). Palliative care - could your patient have been managed at home? Journal of Palliative Care, 8(2), 18-22.

McCaffrey, M., Beebe, A. (1989). Clinical Manual for Nursing Practice. Toronto, C.V. Mosby Co.: 232, 36-38.

Mor, V., Masterson-Allen, M., Houts, P., Siegel, K. (1992). The changing needs of patients with cancer at home. Cancer, 69, 829-838.

Moulin, D.E. et al. (1992). Subcutaneous narcotic infusions for cancer pain: Treatment outcome and guidelines for use. Canadian Medical Association Journal, 146(6), 891-897.

Parkes, C.M. (1978). The management of terminal disease. Psychological Aspects, Saunders, S. (ed.). Philadelphia: E. Arnold Publishers.

Parkes, M., Parkes, J. (1984). "Hospice" versus "hospital" care Reevaluation after 10 years as seen by surviving spouses. Postgraduate Medicine Journal, 60, 120-124.

The Proceedings of Cancer 2000: A report on the work of national task force (1992).

Roe, D.J. (1992). Palliative Care 2000 - Home care. Journal of Palliative Care, $8(1), 28-32$.

Scott, J.F. (1992). Palliative Care 2000 - What's stopping us? Journal of Palliative Care, 8(1), 5-8.

Siegel, K., Raveis, V., Mor, V., Houts, P. (1991). The relationship of spousal caregiver burden to patient disease and treatment-related conditions. Annals of Oncology, 2, 511-516.

Spilling, R. (ed.) (1986). Terminal care at home. Oxford: Oxford University Press, 83-95.

Still, A.W., Todd, C.J. (1986). Role ambiguity in general practice: The care of patients dying at home. Social Science and Medicine, 23(5), 19-25.

Sykes, N., Pearson, S., Chell, S. (1992). Quality of care of the terminally ill: The carer's perspective. Palliative Medicine, 6, 227-236.

Townsend, J., Frank, A.O., Fermont, D. et al. (1990). Terminal cancer care and patients' preference for place of death: A prospective study. British Medical Journal, 301, 415-417.

Twycross, R.G. (1993). Symptom control: The problem areas. Palliative Medicine, 7 (Suppl. 1), 1-8.

Ventafridda, V., Tamburini, M., Caracent, A. et al. (1987). A validation study of the WHO method for cancer pain relief. Cancer, 59, 850.

Wegmann, J. (1987). Hospice home death, hospital death and coping abilities of widows. Cancer Nursing, 10, 148-155.

Wood, M.L. (1993). Communication between cancer specialists and family doctors. Canadian Family Physician, 39, 49-56. 